\title{
Seroprevalence of Toxoplasma gondii infection and risk factors in domestic sheep in Henan province, central China
}

\author{
Nian Zhang ${ }^{1,4, a}$, Shuai Wang ${ }^{1, a,{ }^{*}}$, Dong Wang ${ }^{1}$, Chaoying Li $^{2}$, Zhenchao Zhang ${ }^{1}$, Zhijun Yao ${ }^{1}$, \\ Tingting $\mathrm{Li}^{3}$, Qing Xie ${ }^{1}$, Shiguo Liu ${ }^{1}$, and Haizhu Zhang ${ }^{1}$,* \\ ${ }^{1}$ School of Basic Medical Sciences, Xinxiang Medical University, Xinxiang, Henan 453003, PR China \\ 2 Xinxiang Medical University, Xinxiang, Henan 453003, PR China \\ 3 The Fourth Clinical College, Xinxiang Medical University, Xinxiang, Henan 453003, PR China \\ 4 Xinxiang Assegal Medical Examination Institute, Xinxiang, Henan 453003, PR China
}

Received 31 August 2016, Accepted 13 November 2016, Published online 24 November 2016

\begin{abstract}
Sheep are highly susceptible to infections with Toxoplasma gondii and play a major role in the transmission of toxoplasmosis to humans. In the present study, 779 serum samples from sheep were collected from Henan province, central China from March 2015 to May 2016, and antibodies to T. gondii were detected by modified agglutination test (MAT). The overall seroprevalence of $T$. gondii in sheep was $12.71 \%(99 / 779)$. The risk factors significantly associated with $T$. gondii seroprevalence were the geographical origin, age, presence of cats, and the rearing system. This is the first report of T. gondii infection in sheep in Henan province, central China, and of an association of seropositivity to T. gondii with risk factors.
\end{abstract}

Key words: Toxoplasma gondii, seroprevalence, sheep, MAT, central China.

Résumé - Séroprévalence de l'infection par Toxoplasma gondii et facteurs de risque chez les moutons domestiques dans la province du Henan, Chine centrale. Les moutons sont très sensibles aux infections par Toxoplasma gondii et jouent un rôle majeur dans la transmission de la toxoplasmose aux humains. Dans la présente étude, 779 échantillons de sérum de moutons ont été prélevés dans la province du Henan, en Chine centrale, de mars 2015 à mai 2016, et les anticorps contre T. gondii ont été détectés par le test d'agglutination modifié (MAT). La séroprévalence globale de $T$. gondii chez le mouton était $12.71 \%$ (99/779). Les facteurs de risque significativement associés à la séroprévalence anti- $T$. gondii étaient l'origine géographique, l'âge, la présence de chats et le système d'élevage. Ceci est le premier rapport concernant l'infection par $T$. gondii chez le mouton dans la province du Henan, en Chine centrale, et l'association entre la séropositivité à $T$. gondii et les facteurs de risque.

\section{Introduction}

Toxoplasma gondii is an important protozoan parasite found worldwide that potentially infects all warm-blooded vertebrates, including mammals, birds, and humans $[9,19$, 39]. Sheep are an important intermediate host of T. gondii [36]. Infection of sheep with T. gondii may cause early embryonic death and resorption, fetal death and mummification, abortion, stillbirth, and neonatal death [6, 14, 32], and thus can be responsible for severe economic losses in the sheep industry.

It has been estimated that up to one third of the world's human population has been infected by $T$. gondii $[38,40]$. Humans become infected postnatally, mainly by ingesting tissue cysts from undercooked meat or from food or drink contaminated with oocysts shed in cat feces [22,34]. Ingestion of poorly cooked meat from sheep, and possibly consumption of non-pasteurized contaminated milk from sheep are considered important sources of transmission of T. gondii to humans [4, 7, 18, 21, 27]. People in Henan province have the habit of eating undercooked "barbecue", "kabob", and "instantly boiled mutton", leading to an increased risk of human toxoplasmosis.

There have been a number of surveys of $T$. gondii infection in sheep in many countries $[8,16,26,33]$. In China, several surveys have shown that infection of sheep with $T$. gondii is common in other provinces (Table 1; [25, 42, 45]), but there have been no reports of $T$. gondii infection in sheep in Henan province in central China.

\footnotetext{
${ }^{a}$ Authors with the same contribution to this paper.

*Corresponding authors: tongbaiws1003@163.com; zhanghai zhu@xxmu.edu.cn
} 
Table 1. The prevalence of Toxoplasma gondii infection in sheep in the People's Republic of China.

\begin{tabular}{lccccccc}
\hline Provinces/Cities & Year of sampling $^{\mathrm{A}}$ & Age of sheep & No. tested & No. positive & Prevalence (\%) & Method $^{\mathrm{B}}$ & Reference $^{\text {(\%) }}$ \\
\hline Heilongjiang & $2008-2010$ & Not shown & 792 & 24 & 3.0 & IHA & [37] \\
Liaoning & 2011 & At all ages & 566 & 25 & 7.4 & IHA & [43] \\
Jinzhou & 2012 & At all ages & 402 & 62 & 17.9 & MAT & [42] \\
Qinghai & $2012-2013$ & $\geq 1$ year & 600 & 128 & 21.3 & ELISA & [25] \\
Yunnan & $2012-2013$ & At all ages & 154 & 15 & 9.7 & IHA & [45] \\
Gansu & $2013-2014$ & At all ages & 1732 & 352 & 20.3 & MAT & [44] \\
\hline
\end{tabular}

${ }^{A}$ Years of sampling are listed as published in the references.

${ }^{B}$ IHA: indirect hemagglutination test; MAT: modified agglutination test; ELISA: enzyme-linked immunosorbent assay.

Therefore, the objectives of the present study were to evaluate the seroprevalence of $T$. gondii infection in sheep, and to identify certain risk factors associated with the prevalence of $T$. gondii infection in Henan province, central China.

\section{Materials and methods}

\section{Ethics statement}

The study was reviewed and approved by the Ethics Review Committee of the Xinxiang Medical University (Reference No. 2015016).

\section{The study site}

The study was conducted in Henan province, located in the central part of mainland China, covering an area of $167,000 \mathrm{~km}^{2}$ and having a population of approximately 106 million. Its geographical position is at east longitude $110^{\circ} 21^{\prime}-116^{\circ} 39^{\prime}$ and at north latitude $31^{\circ} 23^{\prime}-36^{\circ} 22^{\prime}$. The Yellow River passes through central Henan. The area has a continental monsoon climate, with four distinctive seasons. The average annual temperature is $12.1-15.7{ }^{\circ} \mathrm{C}$, with a mean annual rainfall of $532.5-1380.6 \mathrm{~mm}$. There are 17 provincial cities distributed in Henan province, with the city of Zhengzhou as its capital. Three cities, including Zhoukou $\left(33^{\circ} 03^{\prime}-34^{\circ} 20^{\prime} \mathrm{N}, 114^{\circ} 05^{\prime}-115^{\circ} 39^{\prime} \mathrm{E}\right)$, Zhumadian $\left(32^{\circ} 18^{\prime}-\right.$ $\left.33^{\circ} 35^{\prime} \mathrm{N}, 113^{\circ} 10^{\prime}-115^{\circ} 12^{\prime} \mathrm{E}\right)$, and Xinxiang $\left(35^{\circ} 18^{\prime} \mathrm{N}\right.$, $113^{\circ} 54^{\prime} \mathrm{E}$ ), were selected for sample collections. All of the above places are the main supply areas for ovine meat to Henan and the neighboring regions.

\section{Sample collection}

A total of 779 blood samples from sheep were collected in the above three cities in Henan province from March 2015 to May 2016. Data regarding age, sex, location, presence of cats, and the rearing system of each animal were recorded. Blood samples were centrifuged and sera were recovered and transferred to $1.5 \mathrm{~mL}$ Eppendorf tubes. Subsequently, all the sera were stored at $-80{ }^{\circ} \mathrm{C}$ until testing for anti-T. gondii antibodies.

\section{Determination of antibodies against $T$. gondii}

Anti-T. gondii antibodies were detected in serum samples by the modified agglutination test (MAT), as described previously $[1,11,44] . T$. gondii whole cell antigen (formalin-treated tachyzoites) was purchased from KeraFAST, Inc. (Boston, MA, USA) and was used to detect $T$. gondii antibodies in deer [30] and chickens [15] by MAT. This antigen was prepared using the RH strain of Toxoplasma cultivated via human foreskin fibroblast cells in culture and the collected tachyzoites were killed by treatment with $6 \%$ formaldehyde for at least 16 hours. In brief, twofold dilutions of sera from $1: 25$ to $1: 3200$ were performed using the serum diluting buffer, and agglutination was performed in U-bottom 96-well microtiter plates using a mixture of $50 \mu \mathrm{L}$ antigen and $50 \mu \mathrm{L}$ diluted sera. The plates were incubated at $37{ }^{\circ} \mathrm{C}$ overnight. The test was considered positive when a layer of agglutinated parasites was formed in wells at dilutions of 1:25 or higher based on previous studies [2, 8]. Positive and negative controls were included in each test.

\section{Statistical analysis}

Differences in $T$. gondii prevalence with different variables such as age, sex, and presence of cats were analyzed using a chi-square test. Statistical analysis was performed using SPSS 20 software for Windows (SPSS Inc., Chicago, Illinois, USA). The differences were considered statistically significant if $p<0.05$.

\section{Results and discussion}

The modified agglutination test (MAT) is a sensitive and specific method for the detection of T. gondii antibodies in a wide range of host species, and is simple, rapid, and of relatively low cost compared to other serological tests $[5,12$, $13,28]$. It has been evaluated extensively in experimentally and naturally infected sheep $[2,8,28]$. Hence, in the present study, we used the MAT to determine the seroprevalence of T. gondii in sheep.

As shown in Table 2, the overall seroprevalence of T. gondii in sheep in Henan province, central China was $12.71 \%$ (99/779). Compared with other provinces in China, the prevalence of $12.71 \%$ in sheep was lower than the prevalence of $20.3 \%$ in Gansu [44], and $21.33 \%$ in Qinghai [25], but higher than the reported prevalence of $3.0 \%$ in Heilongjiang [37], 4.4\% in Liaoning [43], and 9.7\% in Yunnan [45]. These differences may be due to different ecological conditions, climates, serological techniques used, survey periods, sample sizes, and the breed of sheep. 
Table 2. Toxoplasma gondii infection in 779 sheep in Henan province, central China.

\begin{tabular}{|c|c|c|c|c|}
\hline Variable & No. tested & No. positive & Prevalence $(\%)^{\#}$ & $95 \% \mathrm{CI}$ \\
\hline \multicolumn{5}{|l|}{ Region } \\
\hline Zhoukou & 255 & 25 & $9.80^{\mathrm{A}}$ & $6.15-13.45$ \\
\hline Zhumadian & 272 & 20 & $7.35^{\mathrm{A}}$ & $4.25-10.45$ \\
\hline Xinxiang & 252 & 54 & $21.43^{\mathrm{B}}$ & $16.36-26.50$ \\
\hline \multicolumn{5}{|l|}{ Sex } \\
\hline Male & 292 & 34 & 11.64 & $7.96-15.32$ \\
\hline Female & 487 & 65 & 13.35 & $10.33-16.37$ \\
\hline \multicolumn{5}{|l|}{ Age (years) } \\
\hline$\leq 1$ & 246 & 16 & $6.50^{\mathrm{A}}$ & $3.42-9.59$ \\
\hline$\overline{1} \sim 2$ & 292 & 37 & $12.67^{\mathrm{B}}$ & $8.86-16.49$ \\
\hline$\geq 2$ & 241 & 46 & $19.09^{\mathrm{C}}$ & $14.13-24.05$ \\
\hline \multicolumn{5}{|c|}{ Presence of cats } \\
\hline No & 420 & 31 & $7.38^{\mathrm{A}}$ & $4.88-9.88$ \\
\hline Yes & 359 & 68 & $18.94^{\mathrm{B}}$ & $14.89-23.00$ \\
\hline \multicolumn{5}{|c|}{ Rearing system } \\
\hline IR & 221 & 14 & $6.33^{\mathrm{A}}$ & $3.12-9.55$ \\
\hline SIR & 343 & 43 & $12.54^{\mathrm{B}}$ & $9.03-16.04$ \\
\hline Extensive & 215 & 42 & $19.53^{\mathrm{C}}$ & $14.24-24.83$ \\
\hline Total & 779 & 99 & 12.71 & $10.37-15.05$ \\
\hline
\end{tabular}

\footnotetext{
\# Values with different superscript (A, B, C) in the same column are significantly different $(p<0.05)$.
}

Geographically, there are 17 provincial cities distributed in Henan province and three places were selected for screening T. gondii seroprevalence because they were the main supply areas of mutton. The present study showed that geographical origin represents another risk factor. Seropositive animals from different cities were: $9.80 \%$ of 255 from Zhoukou, $7.35 \%$ of 272 from Zhumadian, and $21.43 \%$ of 252 from Xinxiang. The samples collected from Zhoukou and Zhumadian were less likely to show seropositivity compared to those collected from Xinxiang $(p<0.05$; Table 2$)$. This difference may be related to the rearing system in these regions. Most sheep were raised semi-intensively or intensively in Zhoukou and Zhumadian, while extensive and semi-intensive rearing systems were widely used for these small ruminants in Xinxiang.

In the present study, the seroprevalence of $T$. gondii in males was $11.64 \%$ (34/292) and in females $13.35 \%(65 / 487$; Table 2). Although the seroprevalence in females was higher than in males, the difference was not significant $(p>0.05)$. This was consistent with previous reports [3, 20, 41, 45].

Furthermore, the seroprevalence of $T$. gondii infection obtained in the present study in sheep increased significantly $(p<0.05)$ with increasing age. The highest prevalence of infection (19.09\%) was detected in two-year-old or older animals, followed by intermediate prevalence $(12.67 \%)$ in the 1-2 year age group, while the prevalence found in animals in the $\leq 1$ year age group was $6.50 \%$ (Table 2). These results are similar to those of previous investigations [17, 20, 41, 42], suggesting the possibility of horizontal transmission in the investigated herds.

In the present study, the seropositive rate for $T$. gondii of sheep raised on the farm with the presence of cats was higher than that for animals raised on the farm without cats. This finding is also consistent with previous reports $[3,10$, 25]. Liu et al. reported that the odds of the presence of
T. gondii antibodies increased 3.2-fold if cats were present on the farms [25]. Felids are the only known definitive host of $T$. gondii, and primary infected cats shed millions of oocysts into the environment $[24,29]$. Oocysts excreted by cats remain infective for months to years in moist, shaded, and temperature-regulated environmental conditions [23, 35]. The association with the presence of cats is therefore assumed to indicate a causal relationship, and limiting the number of cats on sheep farms is expected to reduce $T$. gondii infections in these small ruminants.

In addition, the seroprevalence obtained in the present study in intensively raised sheep was statistically lower $(p<0.05)$ than that in extensively and semi-intensively raised animals (Table 2). Our findings are similar to those of previous reports [31, 42]. The main reason for such a difference may be that, compared with extensively or semi-intensively raised animals, intensively raised sheep are caged and thus have less chance of ingesting the oocysts of $T$. gondii excreted by infected cats.

\section{Conclusions}

The results of the present survey indicate that $T$. gondii infection is highly prevalent in sheep in Henan province, China. The risk factors significantly associated with $T$. gondii seroprevalence were age, the presence of cats, and the pasturing system on the farms. Integrated and efficient measures are required to prevent and control $T$. gondii infection in sheep in Henan province, China.

\section{Conflict of interest}

We declare that we have no conflict of interest. 
Acknowledgements. This study was supported by the Doctoral Scientific Research Activation Foundation of Xinxiang Medical University (Nos. XYBSKYZZ201504 and XYBSKYZZ201603), the National Natural Science Foundation of China (No. 81502313), and the Key Scientific and Technological Project of Xinxiang City (No. ZG15014).

\section{References}

1. Alvarado-Esquivel C, Garcia-Machado C, Vitela-Corrales J, Villena I, Dubey JP. 2011. Seroprevalence of Toxoplasma gondii infection in domestic goats in Durango State, Mexico. Veterinary Parasitology, 183(1-2), 43-46.

2. Alvarado-Esquivel C, Silva-Aguilar D, Villena I, Dubey JP. 2013. Seroprevalence of Toxoplasma gondii infection in dairy goats in Michoacan State, Mexico. Journal of Parasitology, 99(3), 540-542.

3. Bawm S, Maung WY, Win MY, Thu MJ, Chel HM, Khaing TA, Wai SS, Htun LL, Myaing TT, Tiwananthagorn S, Igarashi M, Katakura K. 2016. Serological survey and factors associated with Toxoplasma gondii infection in domestic goats in Myanmar. Scientifica (Cairo), 2016, 4794318.

4. Boughattas S, Ayari K, Sa T, Aoun K, Bouratbine A. 2014. Survey of the parasite Toxoplasma gondii in human consumed ovine meat in Tunis City. PLoS One, 9(1), e85044.

5. Casartelli-Alves L, Boechat VC, Macedo-Couto R, Ferreira LC, Nicolau JL, Neves LB, Millar PR, Vicente RT, Oliveira RV, Muniz AG, Bonna IC, Amendoeira MR, Silva RC, Langoni H, Schubach TM, Menezes RC. 2014. Sensitivity and specificity of serological tests, histopathology and immunohistochemistry for detection of Toxoplasma gondii infection in domestic chickens. Veterinary Parasitology, 204(3-4), 346-351.

6. Chessa G, Chisu V, Porcu R, Masala G. 2014. Molecular characterization of Toxoplasma gondii Type II in sheep abortion in Sardinia, Italy. Parasite, 21, 6.

7. Chiari Cde A, Neves DP. 1984. Human toxoplasmosis acquired by ingestion of goat's milk. Memórias do Instituto Oswaldo Cruz, 79(3), 337-340.

8. Chikweto A, Kumthekar S, Tiwari K, Nyack B, Deokar MS, Stratton G, Macpherson CN, Sharma RN, Dubey JP. 2011. Seroprevalence of Toxoplasma gondii in pigs, sheep, goats, and cattle from Grenada and Carriacou, West Indies. Journal of Parasitology, 97(5), 950-951.

9. Costache CA, Colosi HA, Blaga L, Gyorke A, Pastiu AI, Colosi IA, Ajzenberg D. 2013. First isolation and genetic characterization of a Toxoplasma gondii strain from a symptomatic human case of congenital toxoplasmosis in Romania. Parasite, 20, 11 .

10. Deng H, Dam-Deisz C, Luttikholt S, Maas M, Nielen M, Swart A, Vellema P, van der Giessen J, Opsteegh M. 2016. Risk factors related to Toxoplasma gondii seroprevalence in indoor-housed Dutch dairy goats. Preventive Veterinary Medicine, 124, 45-51.

11. Dubey JP, Desmonts G. 1987. Serological responses of equids fed Toxoplasma gondii oocysts. Equine Veterinary Journal, 19(4), 337-339.

12. Dubey JP, Thulliez P, Weigel RM, Andrews CD, Lind P, Powell EC. 1995. Sensitivity and specificity of various serologic tests for detection of Toxoplasma gondii infection in naturally infected sows. American Journal of Veterinary Research, 56(8), $1030-1036$.
13. Dubey JR, Fair PA, Bossartt GD, Hill D, Fayer R, Sreekumar C, Kwok OC, Thulliez P. 2005. A comparison of several serologic tests to detect antibodies to Toxoplasma gondii in naturally exposed bottlenose dolphins (Tursiops truncatus). Journal of Parasitology, 91(5), 1074-1081.

14. Edwards JF, Dubey JP. 2013. Toxoplasma gondii abortion storm in sheep on a Texas farm and isolation of mouse virulent atypical genotype $T$. gondii from an aborted lamb from a chronically infected ewe. Veterinary Parasitology, 192(1-3), 129-136.

15. Feng Y, Lu Y, Wang Y, Liu J, Zhang L, Yang Y. 2016. Toxoplasma gondii and Neospora caninum in free-range chickens in Henan Province of China. BioMed Research International, 2016, 8290536.

16. Garcia-Bocanegra I, Cabezon O, Hernandez E, Martinez-Cruz MS, Martinez-Moreno A, Martinez-Moreno J. 2013. Toxoplasma gondii in ruminant species (cattle, sheep, and goats) from southern Spain. Journal of Parasitology, 99(3), 438-440.

17. Gebremedhin EZ, Abdurahaman M, Hadush T, Tessema TS. 2014. Seroprevalence and risk factors of Toxoplasma gondii infection in sheep and goats slaughtered for human consumption in Central Ethiopia. BMC Research Notes, 7, 696.

18. Guo M, Mishra A, Buchanan RL, Dubey JP, Hill DE, Gamble HR, Pradhan AK. 2016. Quantifying the risk of Human Toxoplasma gondii infection due to consumption of domestically produced lamb in the United States. Journal of Food Protection, 79(7), 1181-1187.

19. Hill DE, Dubey JP. 2013. Toxoplasma gondii prevalence in farm animals in the United States. International Journal for Parasitology, 43(2), 107-113.

20. Kamani J, Mani AU, Egwu GO. 2010. Seroprevalence of Toxoplasma gondii infection in domestic sheep and goats in Borno state, Nigeria. Tropical Animal Health and Production, 42(4), 793-797.

21. Kijlstra A, Jongert E. 2008. Control of the risk of human toxoplasmosis transmitted by meat. International Journal for Parasitology, 38(12), 1359-1370.

22. Krueger WS, Hilborn ED, Converse RR, Wade TJ. 2014. Drinking water source and human Toxoplasma gondii infection in the United States: a cross-sectional analysis of NHANES data. BMC Public Health, 14, 711.

23. Lelu M, Villena I, Darde ML, Aubert D, Geers R, Dupuis E, Marnef F, Poulle ML, Gotteland C, Dumetre A, Gilot-Fromont E. 2012. Quantitative estimation of the viability of Toxoplasma gondii oocysts in soil. Applied and Environmental Microbiology, 78(15), 5127-5132.

24. Lilly EL, Wortham CD. 2013. High prevalence of Toxoplasma gondii oocyst shedding in stray and pet cats (Felis catus) in Virginia, United States. Parasites \& Vectors, 6, 266.

25. Liu ZK, Li JY, Pan H. 2015. Seroprevalence and risk factors of Toxoplasma gondii and Neospora caninum infections in small ruminants in China. Preventive Veterinary Medicine, 118(4), 488-492.

26. Lopes AP, Dubey JP, Neto F, Rodrigues A, Martins T, Rodrigues M, Cardoso L. 2013. Seroprevalence of Toxoplasma gondii infection in cattle, sheep, goats and pigs from the North of Portugal for human consumption. Veterinary Parasitology, 193(1-3), 266-269.

27. Luptakova L, Benova K, Rencko A, Petrovova E. 2015. DNA detection of Toxoplasma gondii in sheep milk and blood samples in relation to phase of infection. Veterinary Parasitology, 208(3-4), 250-253. 
28. Mainar-Jaime RC, Barberan M. 2007. Evaluation of the diagnostic accuracy of the modified agglutination test (MAT) and an indirect ELISA for the detection of serum antibodies against Toxoplasma gondii in sheep through Bayesian approaches. Veterinary Parasitology, 148(2), 122-129.

29. Possenti A, Fratini F, Fantozzi L, Pozio E, Dubey JP, Ponzi M, Pizzi E, Spano F. 2013. Global proteomic analysis of the oocyst/sporozoite of Toxoplasma gondii reveals commitment to a host-independent lifestyle. BMC Genomics, 14, 183.

30. Qin SY, Zhang XX, Cong W, Zhou DH, Wang JL, Yin MY, Tan QD, Zhao Q, Zhu XQ. 2014. Seroprevalence and risk factors of Toxoplasma gondii infection in domestic sika deer (Cervus nippon) in northeastern China. Acta Tropica, 140, 184-187.

31. Ragozo AM, Yai RL, Oliveira LN, Dias RA, Dubey JP, Gennari SM. 2008. Seroprevalence and isolation of Toxoplasma gondii from sheep from Sao Paulo state, Brazil. Journal of Parasitology, 94(6), 1259-1263.

32. Rassouli M, Razmi GR, Bassami MR, Movassaghi AR, Azizzadeh M. 2011. Study on ovine abortion associated with Toxoplasma gondii in affected herds of Khorasan Razavi Province, Iran based on PCR detection of fetal brains and maternal serology. Parasitology, 138(6), 691-697.

33. Sharif M, Sarvi S, Shokri A, Hosseini Teshnizi S, Rahimi MT, Mizani A, Ahmadpour E, Daryani A. 2015. Toxoplasma gondii infection among sheep and goats in Iran: a systematic review and meta-analysis. Parasitology Research, 114(1), 1-16.

34. Swierzy IJ, Muhammad M, Kroll J, Abelmann A, Tenter AM, Luder CG. 2014. Toxoplasma gondii within skeletal muscle cells: a critical interplay for food-borne parasite transmission. International Journal for Parasitology, 44(2), 91-98.

35. Torrey EF, Yolken RH. 2013. Toxoplasma oocysts as a public health problem. Trends in Parasitology, 29(8), 380-384.

36. Tzanidakis N, Maksimov P, Conraths FJ, Kiossis E, Brozos C, Sotiraki S, Schares G. 2012. Toxoplasma gondii in sheep and goats: seroprevalence and potential risk factors under dairy husbandry practices. Veterinary Parasitology, 190(3-4), 340-348.
37. Wang CR, Qiu JH, Gao JF, Liu LM, Wang C. 2011. Seroprevalence of Toxoplasma gondii infection in sheep and goats in northeastern China. Small Ruminant Research, 97(1), 130-133.

38. Wang S, Lan C, Zhang L, Zhang H, Yao Z, Wang D, Ma J, Deng J, Liu S. 2015. Seroprevalence of Toxoplasma gondii infection among patients with hand, foot and mouth disease in Henan, China: a hospital-based study. Infectious Diseases of Poverty, 4, 53.

39. Wang S, Wang Y, Sun X, Zhang Z, Liu T, Gadahi JA, Hassan IA, Xu L, Yan R, Song X, Li X. 2015. Protective immunity against acute toxoplasmosis in BALB/c mice induced by a DNA vaccine encoding Toxoplasma gondii elongation factor 1-alpha. BMC Infectious Diseases, 15, 448.

40. Xiao Y, Yin J, Jiang N, Xiang M, Hao L, Lu H, Sang H, Liu X, Xu H, Ankarklev J, Lindh J, Chen Q. 2010. Seroepidemiology of human Toxoplasma gondii infection in China. BMC Infectious Diseases, 10, 4.

41. Xu P, Li X, Guo L, Li B, Wang J, Yu D, Zhao Q, Liu XG. 2014. Seroprevalence of Toxoplasma gondii infection in Liaoning cashmere goat from northeastern China. Parasite, 21, 22.

42. Xu P, Li X, Tang F, Liu YH, Kou X, Zhao ML, Li B, Guo L, Liu XG, Zhao Q. 2015. Seroprevalence and risk factors for Toxoplasma gondii in sheep and goats in Jinzhou, Northeastern China. Tropical Biomedicine, 32(3), 563-567.

43. Yang N, Li H, He J, Mu M, Yang S. 2013. Seroprevalence of Toxoplasma gondii infection in domestic sheep in Liaoning Province, northeastern China. Journal of Parasitology, 99(1), 174-175.

44. Yin MY, Wang JL, Huang SY, Qin SY, Zhou DH, Liu GX, Tan QD, Zhu XQ. 2015. Seroprevalence and risk factors of Toxoplasma gondii in Tibetan Sheep in Gansu province, Northwestern China. BMC Veterinary Research, 11, 41.

45. Zou F, Yu X, Yang Y, Hu S, Chang H, Yang J, Duan G. 2015. Seroprevalence and risk factors of Toxoplasma gondii infection in buffaloes, sheep and goats in Yunnan Province, Southwestern China. Iranian Journal of Parasitology, 10(4), 648-651.

Cite this article as: Zhang N, Wang S, Wang D, Li C, Zhang Z, Yao Z, Li T, Xie Q, Liu S \& Zhang H: Seroprevalence of Toxoplasma gondii infection and risk factors in domestic sheep in Henan province, central China. Parasite, 2016, $23,53$.

Reviews, articles and short notes may be submitted. Fields include, but are not limited to: general, medical and veterinary parasitology; morphology, including ultrastructure; parasite systematics, including entomology, acarology, helminthology and protistology, and molecular analyses; molecular biology and biochemistry; immunology of parasitic diseases; host-parasite relationships; ecology and life history of parasites; epidemiology; therapeutics; new diagnostic tools.

All papers in Parasite are published in English. Manuscripts should have a broad interest and must not have been published or submitted elsewhere. No limit is imposed on the length of manuscripts.

Parasite (open-access) continues Parasite (print and online editions, 1994-2012) and Annales de Parasitologie Humaine et Comparée (1923-1993) and is the official journal of the Société Française de Parasitologie. 